\title{
Novel Electrode Material for Synthesis of Low Concentration Sodium Hypochlorite Solutions
}

\author{
D.V.Girenko ${ }^{1, *}$, A.O. Piletska ${ }^{1}$, A.B.Velichenko ${ }^{1}$, E. Mahé $^{2}$, D. Devilliers ${ }^{2}$ \\ ${ }^{1}$ Ukrainian State University of Chemical Technology, Gagarin ave. 8, 49005 Dnepropetrovsk, Ukraine \\ ${ }^{2}$ Université Pierre et Marie Curie, Laboratoire PECSA-UMR 7195 CNRS, 4 Place Jussieu, 75252 Paris Cedex 05, France \\ *Corresponding Author: dvgir@mail.ru
}

Copyright $@ 2013$ Horizon Research Publishing All rights reserved.

\begin{abstract}
The overpotential of oxygen evolution reaction is $700-800 \mathrm{mV}$ more positive at FTO anode than on $\mathrm{Pt}$ electrode. This property of FTO coating makes it attractive as an electrode material for electrochemical sensors and electroanalytical chemistry. However, oxygen transfer reactions, such as $\mathrm{Pb}^{2+}$ and $\mathrm{Cl}^{-}$oxidation, occur with considerably lower overpotential. It indicates the possibility of formation of oxygen-containing particles which are adsorbed on the FTO surface at $1.5-1.6 \mathrm{~V}$ vs $\mathrm{Ag} / \mathrm{AgCl}$. Similar kinetics of galvanostatic formation of hypochlorite-ions on the Pt and FTO surface can indicate the similar character, surface concentration, and the energy of adsorbed radical-type particles. FTO coating thereby shows high electrocatalytic activity towards the synthesis of sodium hypochlorite during the electrolysis of dilute $\mathrm{NaCl}$ solutions. The preparation of new electrodes with electrocatalytic properties toward oxidation reactions was performed by electrodeposition of lead dioxide onto glass substrates covered with FTO. The modification of FTO electrodes with $\mathrm{PbO}_{2}$ leads to more conductive electrodes with an improved donor density. The electrodes have been designed for oxygen generation.
\end{abstract}

Keywords Fluorine-doped Tin Oxide, Sodium Hypochlorite, Lead dioxide

\section{Introduction}

Noble metal oxides $\left(\mathrm{RuO}_{2}\right.$ and $\left.\mathrm{IrO}_{2}\right)$ have attracted intensive attention due to their metallic conductivity, excellent electrochemical activity, and good stability in aggressive aqueous solutions $[1,2]$. These oxides have now been used as anodic materials, i.e. so-called dimensionally stable anode $\left(\mathrm{DSA}^{\mathbb{B}}\right)$, in a variety of electrochemical applications, including water electrolysis, chlor-alkali production, metal electrowinning, organic synthesis, and in waste water treatment, etc.

Ruthenium based DSA has acquired an excellent reputation for the electrolysis of concentrated $\mathrm{NaCl}$ solutions.
During the electrolysis of dilute $\mathrm{NaCl}$ solutions, degradation of the electrode material occurs. $\mathrm{RuO}_{2}$ is corrosion resistant, but it is not stable enough for long term oxygen evolution [3]. Oxidation to $\mathrm{Ru}(\mathrm{VIII})$ is believed to be part of the reaction mechanism of oxygen evolution on ruthenium [4,5].

Tin dioxide is used in different technological areas, such as optoelectronic devices, gas-sensors, and lithium batteries [6-8]. Some properties can be drastically changed by the addition of adequate dopants. For instance, undoped stoichiometric $\mathrm{SnO}_{2}$ is an insulator, whereas doping with $\mathrm{F}^{-}$ or $\mathrm{Sb}^{5+}$ leads to the generation of semiconductor with metal-like conductivity $[9,10]$. Thin films of tin oxides doped with fluorine have successfully demonstrated their applications as transparent conductors, optical windows for solar spectrum, light emitting diodes, and many more. The combination of high chemical and electrochemical stability as a consequence of the rather large band gap, high electrical conductivity of doped $\mathrm{SnO}_{2}$, and the high oxygen evolution overpotential makes $\mathrm{SnO}_{2}$ an attractive electrode material for the anodic oxidation and oxygen transfer reactions in aqueous solutions [11].

$\mathrm{SnO}_{2}$-based films are grown with wide range of deposition techniques such as sputtering, sol-gel, and various chemical vapour deposition (CVD) techniques [12-13] on almost any inert surface and also on glass [14-15].

Anodic coatings on FTO base can be of interest as "low-cost DSAs" for the electrolysis of low concentration $\mathrm{NaCl}$ solutions and for sodium hypochlorite synthesis, oxygen and ozone production. The possibility of deposition on a glass surface enables to cheapen considerably an anode, to prevent the corrosion damage of metal support.

Electrocatalytic properties of FTO coatings can be changed by modification of surface with noble metals or their oxides as it has been demonstrated for other similar substrates. For example, $\mathrm{Ti} / \mathrm{TiO}_{2} / \mathrm{Pt}$ structures exhibit very interesting electrochemical reactivity [16], and the modification of titanium electrodes by a metallic oxide may lead to the preparation of the well-known DSAs $[17,18]$ or $\mathrm{Ti} / \mathrm{TiO}_{2} / \mathrm{PbO}_{2}$ [19]. It has been reported [20] that $\mathrm{M} / \mathrm{MOx} / \mathrm{Pt}$ electrodes (where M is valve-metal and MOx is its oxide) 
behave like platinum electrodes, but the rate of electron transfer depends on the thickness of the oxide layer.

At the present time the development of new electrode materials for the synthesis of dilute sodium hypochlorite solutions for human and veterinary medicine by the electrolysis of $\mathrm{NaCl}$ solution $(9-27 \mathrm{~g} /$ liter) is of substantial interest.

The objective of this work is to verify the possibility of application of fluorine doped tin dioxide (FTO) as the anode material for the electrolysis of weak $\mathrm{NaCl}$ solutions and oxygen evolution, as well as to study the activity of electrodes consisting of $\mathrm{PbO}_{2}$ nanoparticles dispersed on the surface of FTO.

\section{Materials and Methods}

\subsection{Electrode Substrates}

\section{fluorine doped tin oxide (FTO) (TEC15, Pilkington)}

Commercial fluorine doped tin oxide conductive glass produced by Pilkington (TEC 8 glass, $8 \mathrm{Ohms}, 2.3 \mathrm{~mm}$ glass thickness, FTO 250 to $500 \mathrm{~nm}$ thickness) obtained from Sigma-Aldrich were used as substrates for the preparation of FTO- $\mathrm{PbO}_{2}$ electrodes.

\subsection{The Electrochemical Cell}

A classical three-electrode cell made of PTFE $^{\circledR}$ was used. The area of the exposed surface of the working electrode was $0.4 \mathrm{~cm}^{2}$. The counter electrode was a Pt plate. Prior to each experiment, the cell was cleaned overnight in a concentrated $\mathrm{H}_{2} \mathrm{SO}_{4}-\mathrm{H}_{2} \mathrm{O}_{2}$ mixture, and then rinsed thoroughly with ultrapure water. The cell was connected to a numeric potentiostat (Biologic $\mathrm{VSP}^{\circledR}$ ) controlled via the $\mathrm{EC}$-lab ${ }^{\circledR}$ software. A saturated $\mathrm{Ag} / \mathrm{AgCl}, \mathrm{Cl}^{-}$electrode (SCE) was used in a separate compartment through a porous glass frit, and all the potentials are expressed relatively to it. The cell was regulated at room temperature $20 \pm 1{ }^{\circ} \mathrm{C}$.

\section{3. $\mathrm{PbO}_{2}$ Electrodeposition}

The electrodeposition of $\mathrm{PbO}_{2}$ on FTO substrates was carried out in an electrochemical cell filled with $0.1 \mathrm{M}$ MSA (methanesulphonic acid) $+0.01 \mathrm{M} \mathrm{Pb}(\mathrm{MS})_{2}$ (lead(II) methanesulphonate) solutions by the cycling and galvanostatic methods. The galvanostatic procedure $(4 \mathrm{~mA}$ $\mathrm{cm}^{-2}$ ) was performed during $200 \mathrm{~s}$ at $25^{\circ} \mathrm{C}$.

\subsection{Donor Carrier Concentration}

Determination of donor carrier concentration $\mathrm{N}_{\mathrm{D}}$ (density of donors for n-type semiconductors) was performed according to the standard method given in [19], which consists in the interpretation of FTO Mott-Schottky curves. In this work the dielectric constant for FTO have been taken the experimentally obtained value of 3.74 [21]. For the $\mathrm{PbO}_{2}$ deposit, the dielectric constant, obtained from an experimental determination, has been taken as 3.91 [22,23]. The two dielectric constants can be considered, to a first order approximation, as similar for FTO thin films and $\mathrm{PbO}_{2}$ deposit. From the experimental curves $1 / \mathrm{C}^{2}$ versus $\mathrm{E}$ in $0.1 \mathrm{M}$ perchloric acid, it is possible to get the values of $N_{D}$.

\section{Results and Discussion}

\subsection{Electrochemical Properties of FTO in Acidic Electrolytes}

Hereafter, different solutions which do not contain any $\mathrm{Pb}$ (II) cations or $\mathrm{Cl}^{-}$anions are called "reference electrolytes". Adding $\mathrm{Pb}$ (II) salt with the same anions as in the base electrolyte gives a plating solution.

The first three voltammograms obtained on the sample with FTO coating in $0.1 \mathrm{M} \mathrm{HClO}_{4}$ are presented in Fig 1. It should be noted that similar curves can be obtained in nitric acid, perchloric acid and MSA solutions. Regardless of the nature of electrolyte, on each new sample, the first cycle in the anodic region is significantly different from following ones. The characteristic anodic behaviour during the first cycle can be attributed to the additional oxidation of tin in FTO coating. Shape, current, and hysteresis type during the forward and return scan of potential of the first curve are apparently defined by the degree of reduction of surface during FTO covering and by the following storage conditions. During the second cycle a sharp decrease of anodic current takes place and then the current gradually decreases during the subsequent cycles. After about the $10^{\text {th }}$ cycle, the curves are acceptably reproducible and the potentials of the beginning of current increase as well as the value of current maximum do not depend on the nature of reference electrolyte.

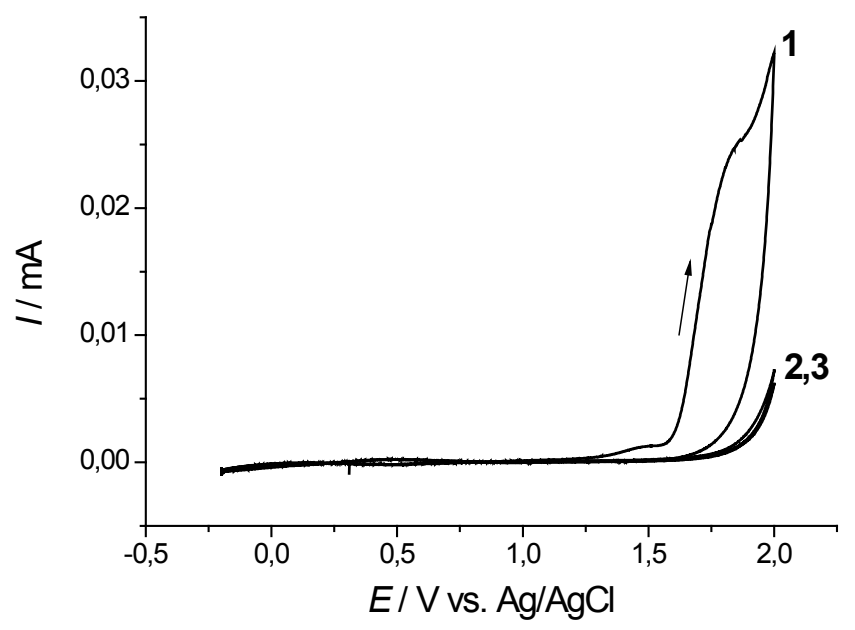

Figure 1. Voltammograms (first three cycles) of a sample with FTO coating $\left(0.4 \mathrm{~cm}^{2}\right)$ in $0.1 \mathrm{M} \mathrm{HClO}_{4} ; \mathrm{v}=10 \mathrm{mV} \mathrm{s}^{-1}$. 
As it can be seen from the analysis of the voltammograms, the FTO surface reveals very low electrochemical activity towards oxygen evolution in acid solutions (Fig. 1). After primary full oxidation of FTO coating, the electrode acts almost as perfectly polarizable in the range from $0 \mathrm{~V}$ to $+1.8 \mathrm{~V}$. In this potential range, the observed current density for the chosen reference electrolytes ( $0.1 \mathrm{M}$ acid solutions) is substantially lower than on the Pt-electrode and is less than 2 $\mu \mathrm{A} \mathrm{cm}{ }^{-2}$. The voltammograms presented in Fig.2 were obtained in a $0.1 \mathrm{M}$ MSA solution. On FTO surface the potential of the beginning of oxygen evolution is 700-800 $\mathrm{mV}$ more positive than on Pt electrode. This property of FTO coating makes it attractive as an electrode material for electrochemical sensors and electroanalytical chemistry.

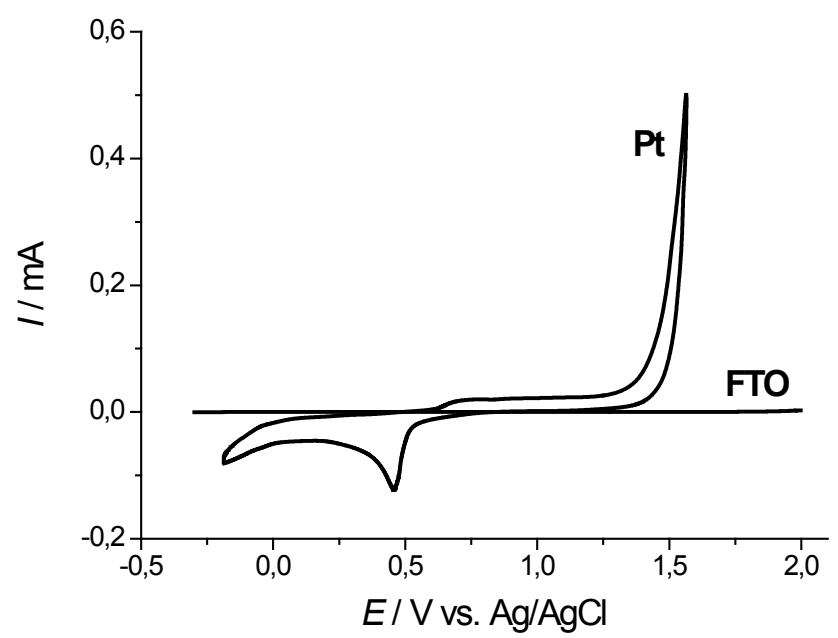

Figure 2. Cyclic voltammograms on a Pt-electrode $\left(0.4 \mathrm{~cm}^{2}\right)$ and on an electrode with FTO coating $\left(0.4 \mathrm{~cm}^{2}\right)$ in $0.1 \mathrm{MMSA} ; \mathrm{v}=10 \mathrm{mV} \mathrm{s}^{-1}$.

\subsection{Deposition of lead dioxide on the FTO surface}

At high anodic potentials most anodic processes, such as oxygen and ozone evolution, oxidation of organic and inorganic substances, take place through the initial stage of formation of radical oxygen-containing particles which are adsorbed on the surface. Since such processes include at least one identical stage, particularly the first stage of formation of adsorbed hydroxyl-radical, they are combined for convenience in one big group called "oxygen-transfer reactions".

The way oxygen-transfer reactions proceed on an electrode with FTO-coating is of interest. As it is known [18-20], for this type of reactions, the high activity of electrode material towards oxygen evolution stage is required, i.e. activity towards the generation of oxygen-containing particles which are adsorbed on the surface.

Electrochemical deposition of lead dioxide is a typical oxygen transfer reaction. It is generally accepted $[24,25]$ that the first stage of $\mathrm{PbO}_{2}$ deposition from acidic solutions is oxidation of water molecules with generation of adsorbed oxygen-containing radical particles like $\mathrm{OH}_{\text {ads }}$. The latter, according to [26-27], oxidize $\mathrm{Pb}$ (II) by chemical mechanism with forming the intermediate $\mathrm{Pb}(\mathrm{III})$ like $\mathrm{PbOH}^{2+}$ which is oxidized with the second electron transfer, leading to $\mathrm{PbO}_{2}$ formation. The potential of the beginning of $\mathrm{PbO}_{2}$ formation is related to oxygen evolution overpotential. For instance, lead dioxide deposition on platinum starts at lower anodic potentials than on gold and vitreous carbon [25].

As a result of low electrocatalytical activity of FTO vs the oxygen evolution reaction, deposition of lead dioxide with noticeable rate thereby can be expected at potentials more anodic than $2.0 \mathrm{~V}$. However, if the FTO-electrode after cyclic polarization in reference electrolyte is moved into $\mathrm{Pb}^{2+}$-containing electrolyte, an anodic current peak which is attributed to lead dioxide formation on the electrode surface is observed at $1.6 \mathrm{~V}$ during the first cycle (Fig. 3). Lead dioxide is reduced during the reverse scan: a typical cathodic current peak is observed at about $1.0 \mathrm{~V}$. Thus, $\mathrm{Pb}$ (II) oxidation on the FTO surface occurs at about the same potentials that on platinum electrode. It can be denoted that the formation of adsorbed oxygen-containing species $\mathrm{OH}_{\text {ads }}$ on FTO surface becomes possible at already 1.5-1.6 V. Further deposition of lead dioxide during the second and the third scans occurs on the surface of just formed lead dioxide nuclei.

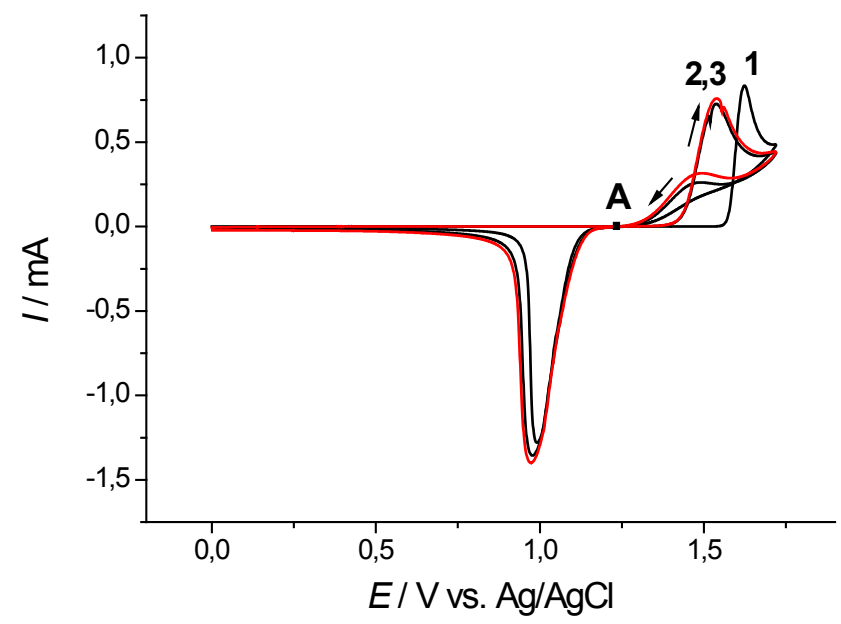

Figure 3. The first three voltammograms at the stationary FTO-coated electrode $\left(0.4 \mathrm{~cm}^{2}\right)$ in a $0.1 \mathrm{M} \mathrm{MSA}+0.01 \mathrm{M} \mathrm{Pb}(\mathrm{MS})_{2}$ solution; $\mathrm{v}=10 \mathrm{mV} \mathrm{s}^{-1}$.

As shown in Fig. 3, the second and following cycles differ from the first: the potential of the beginning of lead dioxide deposition shifts $150 \mathrm{mV}$ to less anodic potentials, as well as the anodic current peak. Such behaviour of the FTO coated electrode can be explained by the fact that during the first reduction scan a layer of undissolved lead oxides is left on the electrode surface. The FTO surface is thereby micro-modified with oxide-hydroxide forms of lead, and the next deposition cycle begins at less positive potentials on the non-foreign surface. A similar behaviour is observed for a nitric acid electrolyte $\left(0.1 \mathrm{M} \mathrm{HNO}_{3}+0.01 \mathrm{M}\right.$ $\left.\mathrm{Pb}\left(\mathrm{NO}_{3}\right)_{2}\right)$ indicating insignificant influence of anion nature. It should be noted that on platinum electrodes, a similar potential shift to less anodic potentials also takes place after the first cycle. 


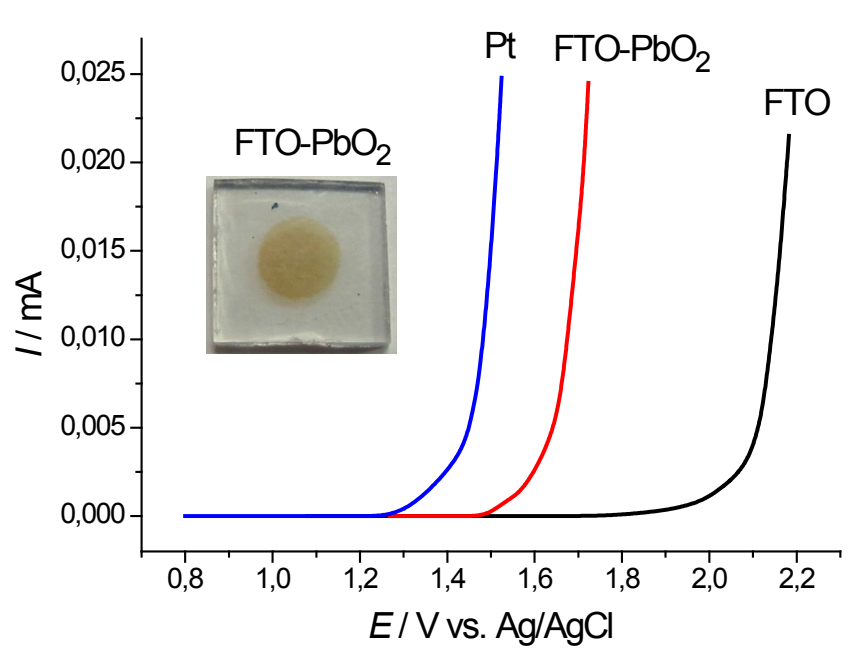

Figure 4. Voltammograms of oxygen evolution on $\mathrm{Pt}\left(0.4 \mathrm{~cm}^{2}\right)$ and on a sample with $\mathrm{FTO}$ and $\mathrm{FTO}-\mathrm{PbO}_{2}$ coating $\left(0.4 \mathrm{~cm}^{2}\right)$ in $0.5 \mathrm{M}$ MSA; $\mathrm{v}=10 \mathrm{mV} \mathrm{s}^{-1}$.

As it was shown above, FTO coating is characterized by quite high oxygen evolution overpotential. Surface modification with the ultrathin film of lead dioxide leads to the substantial decrease of oxygen evolution overpotential almost by $500 \mathrm{mV}$. Thus formed, the coating has high adherence to the surface and corrosion stability in acidic medium. In Fig. 4 the anodic voltammogram of oxygen evolution in 0.5 M MSA solution on a new sample with FTO coating is shown. Curve $\left(\mathrm{FTO}-\mathrm{PbO}_{2}\right)$ is obtained in the same electrolyte, but in this case the electrode surface with FTO coating was previously cyclic polarized in $0.1 \mathrm{M}$ MSA + $0.01 \mathrm{M} \mathrm{Pb}(\mathrm{MS})_{2}$ solution $\left(10 \mathrm{mV} \mathrm{s}^{-1}\right)$. The polarization of this sample was stopped at the potential of $1.25 \mathrm{~V}$ on the cathode sweep at spot A (Fig. 3) before the beginning of lead dioxide reduction.

A glass sample with FTO coating is transparent and colourless. During potential scanning from $+0.6 \mathrm{~V}$ towards anodic region (the first cycle), after $1.6 \mathrm{~V}$ the surface becomes brown as a result of lead dioxide deposition. Gradually the colour of the sample becomes more intense before potentials of $1.25-1.3 \mathrm{~V}$ are reached. At the potentials of the peak of lead dioxide reduction, the colouring of the electrode unevenly diminishes, but the electrode remains coloured during the whole cathodic sweep (to $0.0 \mathrm{~V}$ ) and following anodic sweep up to the beginning of the next cycle of $\mathrm{PbO}_{2}$ deposition. During the second cycle the colour of the electrode becomes more intense at earlier potentials of 1.45-1.5 V. After the second cycle completed, the residual colouring of the electrode becomes more intense and after the third cycle much more intense. Then the residual colouring does not increase so noticeably. It should be noted that the electrode remains transparent. Observed potentials of the beginning of electrode colouring coincide with the beginning of current growth on the anodic sweep of the voltammograms (Fig. 3). In Figure 4, it is shown the photograph of the sample $(1.3 \times 1.3 \mathrm{~cm})$ with deposited in the center ultrathin $\mathrm{PbO}_{2}$ coating $\left(0.4 \mathrm{~cm}^{2}\right)$ by the technique of cyclic potential scanning. The average thickness is about $70-100 \mathrm{~nm}$.

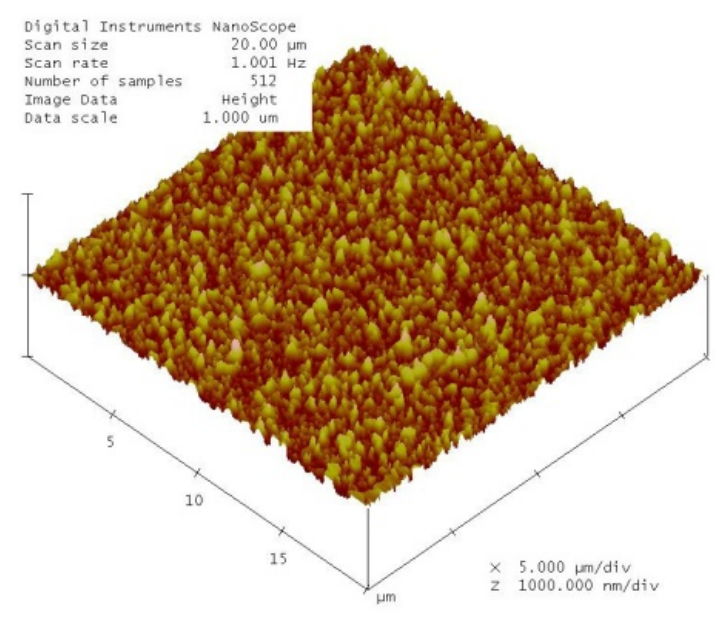

Figure 5. AFM image $20 \mu \mathrm{m} \times 20 \mu \mathrm{m}$ for the sample with FTO coating.

The surface of the initial sample with FTO coating, according to AFM data (Fig. 5), consists of crystals, which size is from 0.2 to $0.5 \mu \mathrm{m}$, with crisp crystal faces. The initial FTO substrate is extremely flat in the nanometer range. The arithmetic average of absolute values of heights over the surface (roughness average $R_{a}$ ) is $32 \mathrm{~nm}$ (Fig. 5). Surface area differential is the difference between the true three dimensional surface area and two dimensional footprint area of the image. The surface area differential was found to be $18 \%$. According to SEM, modification of FTO surface with ultrathin $\mathrm{PbO}_{2}$ film do not change considerably the listed parameters of the surface, morphology almost does not change. Ultrathin $\mathrm{PbO}_{2}$ film forms on the surface of FTO crystals making them less sharp.

This type of modification of FTO surface with micro-amount of active lead dioxide can be interesting for photocatalysis, electrocatalysis and for application in analytical sensors.

\subsection{Sodium hypochlorite generation}

As it was shown above (Fig. 4), micromodification of FTO surface with lead dioxide leads to the decrease of oxygen evolution overpotential by $500 \mathrm{mV}$ in $0.5 \mathrm{M}$ MSA. However, in the presence of $0.15 \mathrm{M} \mathrm{NaCl}$, the polarization of FTO modified with lead dioxide decreases only by $50-100 \mathrm{mV}$, and for non-modified FTO it decreases almost by $400 \mathrm{mV}$ (Fig. 6). It denotes more substantial catalytic activity of FTO coating towards the process of chloride-ions oxidation as compared with the reaction of oxygen evolution. It makes this electrode material promising for the electrolysis of solutions containing chloride-ions.

The influence of micromodification of FTO surface with lead dioxide on electrocatalytic activity was shown on the example of electrolysis of dilute $\mathrm{NaCl}$ solution. 
Voltammograms obtained on the modificated and unmodificated FTO coating in $0.15 \mathrm{M}(0.89 \%) \mathrm{NaCl}$ solution are given in Fig. 6. Presence of lead dioxide nanoparticles on the FTO surface considerably improves electrocatalytic activity of the deposit towards chloride-ions discharge, although this effect is less pronounced as compared with the influence of modification on the oxygen evolution reaction (Fig. 4).

It is interesting to compare the character of voltammograms which reflect total processes of oxygen evolution and chloride-ions oxidation (shown in Fig. 6) with partial data obtained from the electrolysis of $\mathrm{NaCl}$ solution under galvanostatic conditions. For the comparison, we took Pt and FTO electrodes, the platinized titanium anode (Ti-Pt) which was prepared as described in [28], as well as FTO electrodes modified with lead dioxide which i) was deposited by the method of cyclic potential scanning, as it was described above (hereafter this coating is called FTO- $\mathrm{PbO}_{2}(1)$, and ii) was deposited under galvanostatic conditions $\left(4 \mathrm{~mA} / \mathrm{cm}^{2}\right)$ from $0.1 \mathrm{M} \mathrm{MSA}+0.01 \mathrm{M} \mathrm{Pb}(\mathrm{MS})_{2}$ solution during $200 \mathrm{sec}$ (hereafter this coating is called FTO- $\left.\mathrm{PbO}_{2}(2)\right)$. The electrolysis of $0.15 \mathrm{M} \mathrm{NaCl}$ solution in a cell without a separator was carried out for $20 \mathrm{~min}$ at anodic current density of $10 \mathrm{~mA} \mathrm{~cm}{ }^{-2}$. Electrolyte volume was $100 \mathrm{~cm}^{3}, 4 \mathrm{~cm}^{2}$ cathode, FTO, FTO-PbO 2 , Pt and Ti-Pt anodes surface area was $1,6 \mathrm{~cm}^{2}$ each. Electrolysis data are given in Table 1.

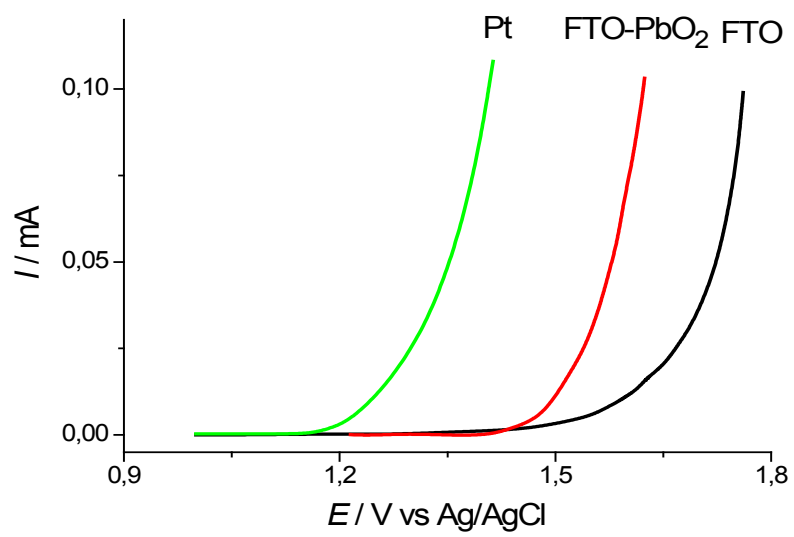

Figure 6. Voltammograms on $\mathrm{Pt}\left(0.4 \mathrm{~cm}^{2}\right)$ and FTO-coating $\left(0.4 \mathrm{~cm}^{2}\right)$, modified and unmodified with lead dioxide, in $0,15 \mathrm{M} \mathrm{NaCl} ; \mathrm{v}=10 \mathrm{mV} \mathrm{s}^{-1}$.

During the electrolysis, maximum amount of sodium hypochlorite was generated on $\mathrm{Pt}$ anode, however, FTO-anodes also showed sufficiently high catalytic activity. But on FTO higher current efficiency of sodium chlorate is observed. Probably it is related to higher anodic potential of the electrode which is observed during the electrolysis. As it can be seen from the table, the others anodic materials reveal lower catalytic activity towards the reaction of sodium hypochlorite synthesis. Higher $\mathrm{CE}$ of oxygen on platinized titanium anode (Ti-Pt) in comparison with metal platinum can be explained by larger true surface and, as a result, lower true current density. FTO samples, modified with lead dioxide in two ways, showed close catalytic activity towards the synthesis of sodium hypochlorite and chlorite.
As follows from the analysis of figure 6 and table 1, Pt and FTO electrodes, having considerably different overpotential of oxygen evolution, showed similar catalytic activity towards synthesis of hypochlorite.

The main processes, occurring under these conditions, are oxygen evolution and chloride-ions oxidation. According to the general opinion $[1,2,25]$, in the region of high anodic potentials the processes of anodic oxidation run through the formation of radical-type particles like $\mathrm{OH}_{\mathrm{ads}}, \mathrm{O}_{\mathrm{ads}}$ and $\mathrm{Cl}_{\mathrm{ads}}$ which are adsorbed on an electrode. These particles can take part in the formation of oxygen-containing chlorine compounds. One of the most probable reactions is formation of hypochlorous acid according to the mechanism of surface recombination (8):

$$
\mathrm{Cl}_{a d s}+\mathrm{OH}_{a d s} \rightarrow \mathrm{HClO}
$$

Accumulation of $\mathrm{ClO}_{3}{ }^{-}$ions as impurity in the solution most probably occurs through the formation of chlorous acid:

$$
\begin{gathered}
\mathrm{HClO}+2 \mathrm{OH}_{a d s} \rightarrow \mathrm{HClO}_{2}+\mathrm{H}_{2} \mathrm{O} \\
\mathrm{HClO}+\mathrm{O}_{\mathrm{ads}} \rightarrow \mathrm{HClO}_{2}
\end{gathered}
$$

The following transformation of chlorous acid into chlorate is a fast stage [31]. This stage can be written as an oxygen transfer reaction:

$$
\mathrm{HClO}_{2}+2 \mathrm{OH}_{a d s} \rightarrow \mathrm{ClO}_{3}^{-}+\mathrm{H}_{2} \mathrm{O}+\mathrm{H}^{+}
$$

As a result of fast reactions (4) at high anodic polarization, chlorous acid does not have time to desorb from the electrode surface and turns fast into chlorate. Thus, we do not discover accumulation of chlorous acid and chlorite-ions in the solution during the electrolysis.

In any case, accumulation of chlorate in the solution starts from the beginning of the electrolysis and its amount grows proportionally to time. It proves the supposition about common mechanism of chlorate and hypochlorite formation through the radical-type particles which form on the surface and are adsorbed. Similar kinetics of hypochlorite-ions formation under galvanostatic conditions on the Pt and FTO surface indicates the similar character, surface concentration, and energy of the adsorbed radical-type particles. Higher potential value on FTO is a result of FTO being n-type semiconductor with not high charge carrier concentration [11]. The donor density of undoped $\mathrm{SnO}_{2}$ thin film is generally considered to be in the $10^{18} \mathrm{~cm}^{-3}$ range of order [30]. Through added dopants, such as fluorine, the donor density can reach $10^{21} \mathrm{~cm}^{-3}$. From the results of Mott-Schottky analysis the donor density of FTO is $2.5 \cdot 10^{21}$, surface modification with ultrathin $\mathrm{PbO}_{2}$ film increases donor density to $8 \cdot 10^{25}$. It can be stated that all observed oxides are n-type semiconductors, and the character of conductivity evolves from highly doped semiconducting for FTO to semi-metallic for the $\mathrm{PbO}_{2}$ deposit [22]. 
Table 1. The concentration of sodium hypochlorite and sodium chlorate, their current efficiency and anodic potentials after 15 min electrolysis of $0.15 \mathrm{M} \mathrm{NaCl}$ solution; anodic current density is $10 \mathrm{~mA} \mathrm{~cm}^{-2}$.

\begin{tabular}{|c|c|c|c|c|c|c|c|}
\hline Anode $\left(1.6 \mathrm{~cm}^{2}\right)$ & $\mathrm{C}(\mathrm{NaClO}), \mathrm{mg} / \mathrm{l}$ & $\mathrm{C}\left(\mathrm{NaClO}_{3}\right), \mathrm{mg} / \mathrm{l}$ & $\mathrm{CE}(\mathrm{NaClO}), \%$ & $\mathrm{CE}\left(\mathrm{NaClO}_{3}\right), \%$ & $\mathrm{CE}\left(\mathrm{O}_{2}\right), \%$ & $\mathrm{pH}$ & $\mathrm{E}, \mathrm{V}$ vs $\mathrm{Ag} / \mathrm{AgCl}$ \\
\hline $\mathrm{Pt}$ & 43.6 & 1.9 & 59 & 5 & 36 & 7.7 & 2.14 \\
\hline FTO & 42.2 & 3.4 & 58 & 10 & 32 & 7.6 & 2.56 \\
\hline FTO-PbO ${ }_{2}(1)$ & 28.8 & 3.4 & 39 & 10 & 51 & 7.5 & 2.25 \\
\hline FTO-PbO $2(2)$ & 28.6 & 4.1 & 39 & 12 & 49 & 7.6 & 2.21 \\
\hline Ti-Pt & 28.5 & 2.1 & 39 & 6 & 55 & 7.1 & 2.18 \\
\hline
\end{tabular}

\section{Conclusions}

FTO coating has shown high electrocatalytic activity towards sodium hypochlorite synthesis during the electrolysis of dilute $\mathrm{NaCl}$ solutions. This electrode material can be used in water disinfection systems, for the synthesis of disinfectant solutions, as well as for the production of sodium hypochlorite solutions for human and veterinary medicine.

The preparation of new electrodes with electrocatalytic properties toward oxidation reactions has been performed by electrodeposition of lead dioxide onto glass substrates covered by FTO. The modification of FTO electrodes with $\mathrm{PbO}_{2}$ leads to more conductive electrodes with an improved donor density.

\section{REFERENCES}

[1] S. Trasatti, G. Lodi. Oxygen and chlorine evolution at conductive metallic oxides in S. Trasatti (Ed.) Electrodes of conductive metallic oxides. Part B. - Amsterdam: Elsevier, Chapter 10, 1981.

[2] S. Trasatti. Electrocatalysis in the anodic evolution of oxygen and chlorine, Electrochim. Acta, Vol. 29, No 11, 1503-1512, 1984.

[3] G.N. Martelli, R. Ornelas, G. Faita. Deactivation mechanisms of oxygen evolving anodes at high current densities, Electrochim. Acta, Vol. 39, No 11-12, 1551-1558, 1994.

[4] R. Kotz, H.J. Lewerenz, S. Stucki. XPS Studies of Oxygen Evolution on $\mathrm{Ru}$ and $\mathrm{RuO}_{2}$ Anodes, J. Electrochem. Soc., Vol. 130, No 4, 825-829, 1983.

[5] J. Xu, M. Wang, G. Liu, J. Li, X. Wang. The physical-chemical properties and electrocatalytic performance of iridium oxide in oxygen evolution, Electrochim. Acta, Vol. 56, No 27, 10223-10230, 2011.

[6] K. Zakrzewska. Mixed oxides as gas sensors, Thin Solid Films, Vol. 391, No 2, 229-238, 2001.

[7] N.C. Li, C.R. Martin. A High-Rate, High-Capacity, Nanostructured Sn-Based Anode Prepared Using Sol-Gel Template Synthesis, J. Electrochem. Soc., Vol. 148, No 2, A164-A170, 2001.

[8] N.L. Wu, J.Y. Hwang, P.Y. Liu, C.Y. Han, S.L. Kuo, K.H. Liao, M.H. Lee, S.Y. Wang. Synthesis and Characterization of Sb-Doped $\mathrm{SnO}_{2}$ Xerogel Electrochemical Capacitor, J.Electrochem. Soc., Vol. 148, No 6, A550-A553, 2001.
[9] S. Shanthi, C. Subramanian, P. Ramasamy. Preparation and properties of sprayed undoped and fluorine doped tin oxide films, Mater. Sci. Eng., Vol. B 57, 127-134, 1999.

[10] E. Shanthi, V. Dutta, A. Banerjee, K.L. Chopra. Electrical and optical properties of undoped and antimony-doped tin oxide films , J. Appl. Phys., Vol. 5, No12, 6243-6251, 1980.

[11] R. Kotz, S. Stucki, B. Carcer. Electrochemical waste water treatment using high overvoltage anodes. Part I: Physical and electrochemical properties of $\mathrm{SnO}_{2}$ anodes, J. Appl. Electrochem., vol.21, No , 14-20, 1991.

[12] A. Facchetti, T.J. Marks. Transparent electronics: from synthesis to applications, Wiley, Oxford, 2010.

[13] E. Arca, K. Fleischer, I.V. Shvets. An alternative fluorine precursor for the synthesis of $\mathrm{SnO} 2: \mathrm{F}$ by spray pyrolysis, Thin Solid Films, Vol.520, No 6, 1856-1861, 2012.

[14] M. Girtan, A. Bouteville, M. Rusu, G.G. Rusu. Preparation and properties of $\mathrm{SnO} 2$ : F thin films, Journal of Optoelectronics and Advanced Materials, Vol.8, No, 27-30, 2006.

[15] G.G. Amatucci, N. Pereira. Fluoride based electrode materials for advanced energy storage devices, J. Fluorine Chem, Vol.128, No , 243-262, 2007.

[16] D. Devilliers, E. Mahe, Modified titanium electrodes, in: M. Nunez (Ed.), Trends in Electrochemistry Research, Nova Science Publishers Inc, New York, 2007.

[17] Ch. Comninellis, G.P. Vercesi. Problems in DSA coatings deposition by thermal decomposition, J. Appl. Electrochem, Vol. 21, No 2, 136-142, 1991.

[18] A. Cornell, B. Hakansson, G. Lindbergh. Ruthenium based DSA in chlorate electrolysis - critical anode potential and reaction kinetics, Electrochim. Acta, Vol. 48, No 5, 473-481, 2003.

[19] D. Devilliers, E. Mahe. Modified titanium electrodes Application to $\mathrm{Ti} / \mathrm{TiO} 2 / \mathrm{PbO}_{2}$ dimensionally stable anodes, Electrochim. Acta, Vol. 55, No 27, 8207-8214, 2010.

[20] E. Mahe, D. Devilliers, H. Groult, J. Pouilleau. Electrochemical behaviour of platinum-coated $\mathrm{Ta} / \mathrm{Ta}_{2} \mathrm{O}_{5}$ electrodes, Electrochim. Acta, Vol. 44, No 13, 2307-2315, 1999.

[21] S. Belgacem, R. Bennaceur. Propriétés optiques des couches minces de $\mathrm{SnO}_{2}$ et $\mathrm{CuInS}_{2}$ airless spray, Rev. Phys. Appl., Vol. 25, No 12, 1245-1258, 1990.

[22] D. J. Payne, R.G. Egdell, W. Hao, J.S. Foord, A. Walsh, G.W. Watson. Why is lead dioxide metallic?, Chem. Phys. Lett., Vol. 411, No 1-3, 181-185, 2005.

[23] D. J. Payne, G. Paolicelli, F. Offi, G. Panaccione, P. Lacovig, G. Beamson, A. Fondacaro, G. Monaco, G. Vanko, R.G. 
Egdell. A study of core and valence levels in $\beta-\mathrm{PbO}_{2}$ by hard X-ray photoemission, J Electron Spectrosc Related Phenom, Vol.169, No 1, 26-34, 2009.

[24] M. Fleischmann, H.R. Thirsk. The potentiostatic study of the growth of deposits on electrodes, Electrochim. Acta, Vol. 1, No, 146-160, 1959.

[25] H. Chang, D.C. Johnson. Electrocatalysis of anodic oxygen-transfer reactions - Chronoamperometric and voltammetric studies of the nucleation and electrodeposition of beta-lead dioxide at a rotated gold disk electrode in acidic media, J. Electrochem. Soc., Vol. 136, No 2, 17-22, 1989.

[26] A.B. Velichenko, D.V. Girenko, F.I. Danilov. Mechanism of lead dioxide electrodeposition, J. Electroanal. Chem., Vol. 405, No 1-2, 127-132, 1996.
[27] A.B. Velichenko, D.V. Girenko, S.V. Kovalyov, F.I. Danilov. Kinetics of the lead dioxide electrodeposition from a nitrate electrolyte, Russ. J. Electrochem., Vol. 35, 1250-1253, 1999.

[28] O. Kasian, T. Luk!yanenko, A. Velichenko. Oxidation of Cr3+-Ions at the Composite TiOx/PtOy Electrode, ECS Transactions, Vol. 45, No 9, 13-18, 2013.

[29] R.E. White, J.O'M. Bockris, B.E. Conway. Modern Aspects of Electrochemistry, New York, Plenum Press, Vol. 18, 1986.

[30] H. L. Hartnagel, A. L. Dawar, A. K. Jain, C. Jagadish. Semiconducting Transparent Thin Films, Institute of Physics Publishing, Philadelphia, 1995.

[31] M.S. Siddiqui. Chlorine-Ozone Interactions: Formation of Chlorate, Water Research, Vol. 30, No 9, 2160-2170, 2006. 